\title{
NanoSIMS Analysis of Bacillus Spores for Forensics
}

\author{
P.K. Weber, ${ }^{*}$ M.L. Davisson, ${ }^{*}$ and S.P. Velsko* \\ * Lawrence Livermore National Laboratory, Livermore, CA 94550
}

The threat associated with the potential use of radiological, nuclear, chemical and biological materials in terrorist acts has resulted in new fields of forensic science requiring the application of state-of-the-science analytical techniques. Since the anthrax letter attacks in the United States in the fall of 2001, there has been increased interest in physical and chemical characterization of bacterial spores [1-11]. While molecular methods are powerful tools for identifying genetic differences, other methods may be able to differentiate genetically identical samples based on physical and chemical properties, as well as provide complimentary information, such as methods of production and approximate date of production.

Microanalysis has the potential to contribute significantly to microbial forensics. Bacillus spores are highly structured, consisting of a core, cortex, coat, and in some species, an exosporium [12]. This structure provides a template for constraining elemental abundance differences at the nanometer scale $[9,10,13,14]$. The primary controls on the distribution of major elements in spores are likely structural and physiological. For example, $\mathrm{P}$ and $\mathrm{Ca}$ are known to be abundant in the spore core because that is where P-rich nucleic acids and Cadipicolinic acid are located, respectively. Trace elements are known to bind to the spore coat [13, 15], but the controls on these elements are less well understood. Elemental distributions and abundances may be directly related to spore production, purification and stabilization methodologies, which are of particular interest for forensic investigation. To this end, we are developing a high-resolution secondary ion mass spectrometry method using a Cameca NanoSIMS 50 to study the distribution and abundance of trace elements in bacterial spores.

In this presentation we will review and compare methods for preparing and analyzing samples, as well as review results on the distribution and abundance of elements in bacterial spores. We use NanoSIMS to directly image samples as well as depth profile samples. The directly imaged samples are sectioned to present a flat surface for analysis. We use focused ion beam (FIB) milling to top-cut individual spores to create flat surfaces for NanoSIMS analysis [11]. Depth profiling can be used on whole spores, which are consumed in the process of analysis [9]. The two methods generate comparable results, with the expected distribution of $\mathrm{P}$ and $\mathrm{Ca}$. Ca-compatible elements, such as $\mathrm{Mg}$ and $\mathrm{Mn}$, are found to follow the distribution of Ca. The distribution of other elements will be discussed.

We envision the first application of this methodology will be to sample matching for trace samples. Towards this end, we are generating a baseline data set for samples produced by multiple laboratories. Preliminary results suggest that this method provides significant probative value for identifying samples produced by the same method in the same laboratory, as well as coming from the same initial production run. The results of this study will be presented. 
[1] A. J. Westphal, P. B. Price, T. J. Leighton and K. E. Wheeler, Proceedings of the National Academy of Science (USA) 100 (2003) 3461-3466.

[2] V. Ryzhov, Y. Hathout and C. Fenselau, Applied and Environmental Microbiology 66 (2000) 3828-3834.

[3] J. R. Whiteaker, C. Fenselau, D. Fetterolf, D. Steele and D. Wilson, Analytical Chemistry 76 (2004) 2836-2841.

[4] J. B. Cliff, K. H. Jarman, N. B. Valentine, S. L. Golledge, D. J. Gaspar, D. S. Wunschel and K. L. Wahl, Applied and Environmental Microbiology 71 (2005) 6524-6530.

[5] C. M. Gikunju, S. M. Lev, A. Birenzvige and D. M. Schaefer, Talanta 62 (2004) 741-744.

[6] J. Horita and A. A. Vass, Journal of Forensics Science 48 (2003) 1-5.

[7] H. W. Kreuzer-Martin, M. J. Lott, J. V. Dorigan and J. R. Ehleringer, Proceedings of the National Academy of Sciences (USA) 100 (2003) 815-819.

[8] H. W. Kreuzer-Martin, L. A. Chesson, M. J. Lott, J. V. Dorigan and J. R. Ehleringer, Journal of Forensics Science 49 (2004) 1-7.

[9] S. Ghosal, S. J. Fallon, T. Leighton, K. E. Wheeler, I. D. Hutcheon and P. K. Weber, Analytical Chemistry 80 (2008) 5986-5992.

[10] L. N. Brewer, J. A. Ohlhausen, P. G. Kotula and J. R. Michael, Forensic Science International 179 (2008) 98-106.

[11] P. K. Weber, G. A. Graham, N. E. Teslich, W. M. Chan, S. Ghosal, T. J. Leighton and K. E. Wheeler, Journal of Microscopy (2009) in press.

[12] P. Gerhardt, H. S. Pankratz and R. Scherrer, Applied and Environmental Microbiology 32 (1976) 438-440.

[13] M. Stewart, A. P. Somlyo, A. V. Somlyo, H. Suman, J. A. Lindsay and W. G. Murrell, Journal of Bacteriology 143 (1980) 481-491.

[14] M. Stewart, A. P. Somlyo, A. Somlyo, H. Suman, J. A. Lindsay and W. G. Murrell, Journal of Bacteriology 147 (1981) 670-674.

[15] L. M. He and B. M. Tebo, Applied and Environmental Microbiology 64 (1998) 11231129.

[16] This research was supported by LLNL Laboratory Directed Research and Development and the Department of Homeland Security under the auspices of the U.S. Department of Energy under Contract DE-AC52-07NA27344. 